\title{
Vertical pons hyperintensity and hot cross bun sign in cerebellar-type multiple system atrophy and spinocerebellar ataxia type 3
}

\author{
Atsuhiko Sugiyama ${ }^{1 *}$ DD, Hajime Yokota², Yoshitaka Yamanaka', Hiroki Mukai², Tatsuya Yamamoto 1,3, \\ Shigeki Hirano ${ }^{1}$, Kyosuke Koide ${ }^{1}$, Shoichi Ito ${ }^{1,4}$ and Satoshi Kuwabara ${ }^{1}$
}

\begin{abstract}
Background: The "hot cross bun" (HCB) sign, a cruciform hyperintensity in the pons on magnetic resonance imaging (MRI), has gradually been identified as a typical finding in multiple system atrophy, cerebellar-type (MSA-C). Few reports have evaluated the sensitivity of an HCB, including a cruciform hyperintensity and vertical line in the pons, which precedes a cruciform hyperintensity, in the early stages of MSA-C. Moreover, the difference in frequency and timing of appearance of an HCB between MSA-C and spinocerebellar ataxia type 3 (SCA3) has not been fully investigated.

Methods: This study investigated the time at which an HCB and orthostatic hypotension $(\mathrm{OH})$ appeared in 41 patients with MSA-C, based on brain MRI and head-up tilt test. The MRI findings were compared with those of 26 patients with SCA3. The pontine signal findings on T2-weighted MRI were graded as 0 (no change), 1 (a vertical T2 high-intensity line), or 2 (a cruciform T2 high-intensity line), with grades 1 or 2 considered as an HCB. OH 30/15 was defined as a decrease in systolic blood pressure of $>30 \mathrm{mmHg}$ or diastolic blood pressure of $>15 \mathrm{mmHg}$.
\end{abstract}

Results: Among the 24 patients with MSA-C within 2 years from the onset of motor symptoms, an HCB was detected in $91.7 \%$, whereas $\mathrm{OH} 30 / 15$ was present in 60.0\%. Among the 36 patients with MSA-C within 3 years from the onset of motor symptoms, a grade $2 \mathrm{HCB}$ was detected in $66.7 \%$ of those with MSA-C but in none of those with SCA-3.

Conclusions: $\mathrm{HCB}$ is a highly sensitive finding for MSA-C, even in the early stages of the disease. A grade $2 \mathrm{HCB}$ in the early stage is an extremely specific finding for differentiating MSA-C from SCA-3.

Keywords: Multiple system atrophy, Magnetic resonance imaging, Hot cross bun sign, Spinocerebellar ataxia type 3, Orthostatic hypotension

\section{Background}

Multiple system atrophy (MSA) is a progressive, adultonset neurodegenerative disorder characterized by various combinations of autonomic failure, parkinsonism, cerebellar ataxia, and pyramidal signs. The current

\footnotetext{
* Correspondence: chinneosyo0624@yahoo.co.jp

'Department of Neurology, Graduate School of Medicine, Chiba University, Chiba, Japan

Full list of author information is available at the end of the article
}

consensus criteria, which were revised in 2008, have been widely accepted as the diagnostic guideline for MSA [1]. In the second consensus criteria, autonomic failure, including orthostatic hypotension $(\mathrm{OH})$ and/or urogenital symptoms, is an essential clinical parameter [1]. However, the second consensus criteria are not sensitive for the diagnosis of early-stage MSA. A validation study on the second consensus criteria showed that the sensitivity for probable MSA at the first visit was only

\section{BMC}

(c) The Author(s). 2020 Open Access This article is licensed under a Creative Commons Attribution 4.0 International License, which permits use, sharing, adaptation, distribution and reproduction in any medium or format, as long as you give appropriate credit to the original author(s) and the source, provide a link to the Creative Commons licence, and indicate if changes were made. The images or other third party material in this article are included in the article's Creative Commons licence, unless indicated otherwise in a credit line to the material. If material is not included in the article's Creative Commons licence and your intended use is not permitted by statutory regulation or exceeds the permitted use, you will need to obtain permission directly from the copyright holder. To view a copy of this licence, visit http://creativecommons.org/licenses/by/4.0/ The Creative Commons Public Domain Dedication waiver (http://creativecommons.org/publicdomain/zero/1.0/) applies to the data made available in this article, unless otherwise stated in a credit line to the data. 
$18 \%$ and that for possible MSA based on the first consensus was $41 \%$ [2]. Therefore, it is important to overcome the poor sensitivity of the second consensus criteria in MSA diagnosis during the early stages of the disease.

In the second consensus criteria, magnetic resonance imaging (MRI) does not play a major role in diagnosis. Atrophy of the putamen, middle cerebellar peduncle, pons, or cerebellum on MRI was only included as an additional feature of possible MSA [1]. However, other conventional MRI features have been widely used to diagnose MSA or to rule out other possible diagnoses [3]. The "hot cross bun" (HCB) sign, that is, a cruciform hyperintensity in the pons on T2-weighted imaging (T2WI), was named for the Easter pastry it resembles and was reported to be a typical feature of MSA $[4,5]$. Initially, only a vertical line is seen, but with disease progression, it becomes cruciform with the addition of a horizontal line $[6,7]$. In the early stages of the disease, a cruciform hyperintensity in the pons is not very sensitive, and a Japanese study with a large cohort revealed that a cruciform hyperintensity was detected in $64.0 \%$ of patients with MSA-C who underwent brain MRI within 2 years after the onset of motor impairment [8]. Although focusing on a vertical line preceding a cruciform hyperintensity in the pons may increase sensitivity, few reports have examined the sensitivity of a vertical hyperintensity in the pons in the early disease stage.

One reason why the $\mathrm{HCB}$ is not included in the current consensus criteria [1] may be that the sign is not specific to MSA. It can also be observed in various forms of spinocerebellar ataxia (SCA), including SCA1, 2, 3, 7, 8, and 34 [9, 10]. SCA3 is a common autosomal dominant cerebellar ataxia that occurs in most populations [11]. Moreover, in Japan, SCA3 is the most common SCA in which the HCB can be observed [12]. Hence, identifying differences between MSA and SCA3 is important in progressive ataxia cases in which an HCB is seen on brain MRI, especially in Japan. As disease progression rates of MSA and SCA-3 differ $[8,13]$, the timing of HCB appearance is expected to differ between MSA and SCA-3. However, the difference between MSA and SCA3 in terms of the frequency and timing of appearance of the HCB has not been fully investigated.

We hypothesized that a vertical hyperintensity in the pons is a highly sensitive MRI finding in the early disease course of MSA-C and that the appearance of an HCB early in the disease course is a specific MRI finding for differentiating MSA-C from SCA3. This study compared the frequency and timing of $\mathrm{HCB}$ appearance in the disease course between patients with MSA (either parkinsonian or cerebellar) and SCA3.

\section{Methods \\ Subjects}

This retrospective study was approved by the institutional review board of our institution, and the need for informed consent was waived. Inclusion criteria for patients with MSA were as follows: admission between April 2010 and December 2017, having undergone $1.5 \mathrm{~T}$ MRI, and clinically confirmed probable MSA based on the diagnostic categories in the second consensus statement [1]. Diagnosis of probable MSA was confirmed by a movement disorder specialist at our center.

In total, 81 patients with MSA were identified, of whom 1 was excluded because of a previous history of putaminal hemorrhage, leaving 80 included in the study. One of the 80 patients underwent postmortem examination of the brain, and the diagnosis was pathologically confirmed. The inclusion criteria for patients with SCA3 were a genetically confirmed SCA3 diagnosis, an examination at our institution between December 2003 and June 2018, and having undergone a 1.5 Tesla MRI test. A total of 26 patients with SCA3 were identified, and none were excluded because of a history of any other central nervous system disorder. Conversely, the inclusion criteria for control subjects were consecutive patients who were referred to our hospital with complaints of headache or dizziness and had no neurologic abnormalities and who had undergone a 1.5 Tesla MRI test between October 2007 and March 2018. In total, 22 control subjects were included in the study.

At the time of diagnosis of probable MSA, it was classified according to whether the clinical syndrome was dominated by parkinsonism (MSA-P) or cerebellar ataxia (MSA-C). The medical records of all patients were reviewed for age at onset, age at MRI, and disease duration from onset to MRI. Disease onset was defined as the initial presentation of any motor problem. The results of head-up tilt tests were reviewed in patients with MSA.

\section{Image interpretation}

All MRI examinations had been performed as part of routine clinical care, and T2WI data were available for all patients. Among the 80 patients with MSA, 125 MRI scans were performed. Among the 26 patients with SCA3, 50 MRI results were available for evaluation, whereas among the 22 control subjects, 22 MRIs were available for evaluation. Two board-certified neuroradiologists (H.Y. and H.M., with 13 and 11 years of experience, respectively) who were blinded to the clinical data independently evaluated the MRIs for each subject. When interpretations differed, the final result was determined by consensus of the two neuroradiologists and a board-certified neurologist (A.S., with 11 years of experience). 
We graded the pontine signal findings as 0 , with no changes seen; 1 , when a vertical T2 high-intensity line began to appear or a clear vertical line was present; and 2, when a horizontal line began to appear along with a vertical line or clear horizontal and vertical lines were seen in the ventral pons (Fig. 1). In this study, both grade 1 and grade 2 were defined as an HCB.

\section{Assessment for orthostatic hypotension}

The head-up tilt test was performed for patients with MSA in a quiet room at an ambient temperature of $22{ }^{\circ} \mathrm{C}$ to $26^{\circ} \mathrm{C}$. Each subject lay supine on the table for at least $15 \mathrm{~min}$ before the test. Blood pressure and heart rate were measured using a sphygmomanometer at 1-min intervals during the test. After $5 \mathrm{~min}$ of baseline measurements, the subject was passively tilted on the electrically driven tilt table to $70^{\circ}$ for 10 min. Some patients had more than one tilt table test, so that 120 results for the 80 patients with MSA were available. Based on the diagnostic criteria for probable MSA, "OH 30/15" was defined as a decrease in systolic blood pressure of at least $30 \mathrm{mmHg}$ or a decrease in diastolic blood pressure of at least $15 \mathrm{mmHg}$ within $3 \mathrm{~min}$ of tilting [1] and "OH 20/10" was defined as a decrease in systolic blood pressure of at least $20 \mathrm{mmHg}$ or a decrease in diastolic blood pressure of at least $10 \mathrm{mmHg}$ within $3 \mathrm{~min}$ of tilting [14].

\section{Statistical analysis}

SPSS software, ver. 25.0 (SPSS Japan, Tokyo, Japan), was used to perform all statistical analyses. The demographic variables of patients with MSA and SCA3 and control subjects were compared using the Kruskal-Wallis oneway analysis of variance with post hoc Mann-Whitney $U$ test adjusted for multiple comparisons for age at MRI and frequency of MRI and the $\chi^{2}$ test for the gender. However, the demographic variables of patients with
MSA or SCA3 were compared using a $t$-test and the Mann-Whitney $U$ test for continuous variables. The $x^{2}$ and Fisher's exact probability tests were used to compare the prevalence of the $\mathrm{HCB}$ sign between patients with MSA-C, SCA3, and controls. The $t$-test and the MannWhitney $U$ test were used to compare disease duration at the first report of an $\mathrm{HCB}$ in patients with MSA-C or SCA3.

\section{Results}

Among the 80 patients with MSA, 41 were classified as having MSA-C and 39 with MSA-P. The demographics of the subject groups included in the study are shown in Table 1 . There were no statistically significant differences noted in the sex distribution of the subjects. On comparing patients with MSA and SCA3 and control subjects, it was found that patients with MSA were older than the patients with SCA3 when MRI was performed $(p=0.003)$ and were older than patients with SCA3 at disease onset $(p<0.001)$. Moreover, patients with SCA3 had longer disease duration at the time of MRI than those with MSA $(p<0.001)$. The control subjects underwent MRI tests less frequently than patients with MSA and SCA3 $(p<0.001$ and $p=0.001)$. On comparing patients with MSA-C and SCA3 and control subjects, it was found that patients with MSA-C were older than the patients with SCA3 at disease onset $(p<0.001)$. Also, patients with SCA3 had longer disease duration at the time of MRI than those with MSA-C $(\mathrm{p}<0.001)$. The control subjects underwent MRI tests less frequently than patients with MSA-C $(p=0.001)$.

\section{Hot cross bun sign in MSA and SCA3}

The $\mathrm{K}$ value of the interrater variability between the two examiners who evaluated the $\mathrm{HCB}$ was 0.882 . The frequencies of HCB signs observed in MSA, SCA3, and controls are listed in Table 2. The frequencies of $\mathrm{HCB}$

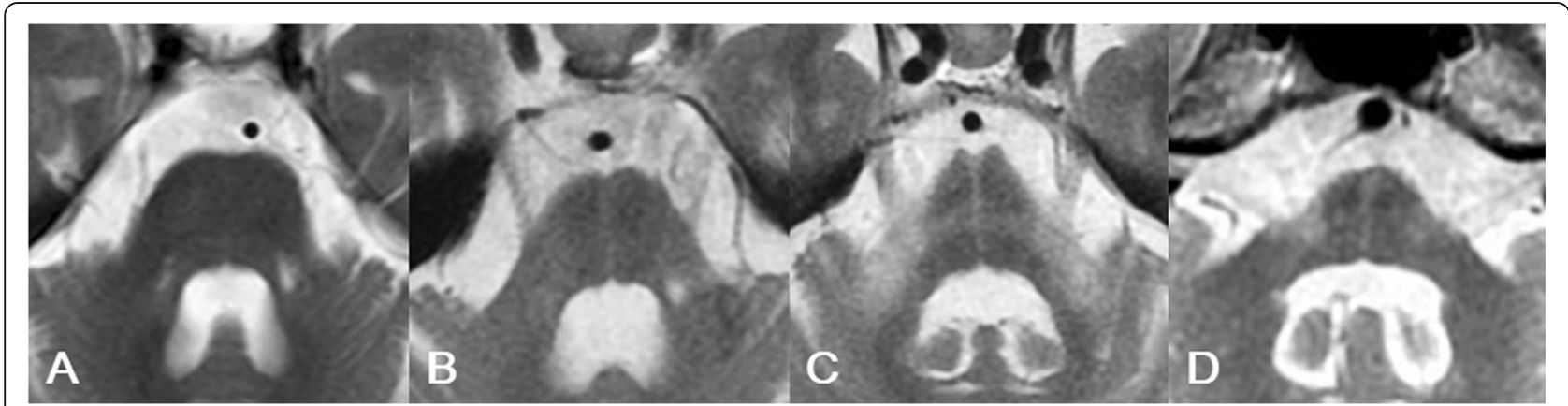

Fig. 1 Three grades of the hot cross bun (HCB) sign on magnetic resonance imaging. a Grade 0 (negative) HCB sign in a 74-year-old woman with cerebellar-type multiple system atrophy (MSA-C) with a disease duration of 0.3 years. There is no signal change in the ventral pons. $\mathbf{b}$ Grade 1 HCB sign in a 74-year-old woman with MSA-C with a disease duration of 2.3 years. A vertical T2 high-intensity line is clearly seen in the ventral pons. c Grade 2 HCB sign in a 61-year-old man with MSA-C with a disease duration of 2.3 years. Both horizontal and vertical lines are clearly seen in the ventral pons. d Grade 2 HCB sign in a 75-year-old woman with SCA3 with a disease duration of 8.2 years. Both horizontal and vertical lines are clearly seen in the ventral pons 
Table 1 Demographics of the patients with MSA, SCA3, and the controls

\begin{tabular}{|c|c|c|c|c|c|}
\hline & $\begin{array}{l}\text { Sex Distribution } \\
\text { (Male/Female) }\end{array}$ & $\begin{array}{l}\text { Age at MRI } \\
\text { (years, median, range) }\end{array}$ & $\begin{array}{l}\text { Age at Onset }{ }^{c} \\
\text { (years, mean } \pm S D \text { ) }\end{array}$ & $\begin{array}{l}\begin{array}{l}\text { Disease Duration } \\
\text { (years, median, range) }\end{array} \\
\end{array}$ & $\begin{array}{l}\text { Frequency of } \mathrm{MRI}^{\mathrm{b}} \\
\text { (times, median, range) }\end{array}$ \\
\hline MSA $(n=80)$ & $40 / 40$ & $67.0(46-82)$ & $63.2 \pm 8.7$ & $2.2(0.2-8.3)$ & $1(1-5)$ \\
\hline MSA-C $(n=41)$ & $21 / 20$ & $63.5(46-82)$ & $61.3 \pm 9.9$ & $2.1(0.2-8.3)$ & $1(1-5)$ \\
\hline $\operatorname{SCA3}(n=26)$ & $10 / 16$ & $58.5(24-82)$ & $46.0 \pm 17.2$ & $6.7(0.8-24.0)$ & $1(1-6)$ \\
\hline Controls $(n=22)$ & $11 / 11$ & $64.0(42-82)$ & NA & NA & $1(1-1)$ \\
\hline$P$ value for MSA vs. SCA3 & NA & NA & $<0.001$ & $<0.001$ & NA \\
\hline$P$ value for MSA-C vs. SCA3 & NA & NA & $<0.001$ & $<0.001$ & NA \\
\hline $\begin{array}{l}P \text { value for group comparison } \\
\text { (MSA, SCA3, Controls) }\end{array}$ & 0.575 & 0.01 & NA & NA & 0.002 \\
\hline $\begin{array}{l}\text { P value for group comparison } \\
\text { (MSA-C, SCA3, Controls) }\end{array}$ & 0.568 & 0.107 & NA & NA & 0.003 \\
\hline \multicolumn{6}{|c|}{$P$ value for post-hoc group comparisons } \\
\hline MSA vs. SCA3 & NA & 0.003 & NA & NA & 0.597 \\
\hline MSA vs. Controls & NA & 0.235 & NA & NA & $<0.001$ \\
\hline SCA3 vs. Controls & NA & 0.191 & NA & NA & 0.001 \\
\hline MSA-C vs. SCA3 & NA & NA & NA & NA & 0.713 \\
\hline MSA-C vs. Controls & NA & NA & NA & NA & 0.001 \\
\hline
\end{tabular}

${ }^{a}$ Chi-squared test (post-hoc chi-squared tests adjusted for multiple comparison: $P<0.05 / 3=0.0167$ )

${ }^{\mathrm{b}}$ Nonparametric test (Kruskal-Wallis 1-way ANOVA with post-hoc Mann-Whitney $U$ test adjusted for multiple comparison: $\mathrm{P}<0.05 / 3=0.0167$ )

'Student's t-test

${ }^{\mathrm{d}}$ Mann-Whitney $U$ test

signs among MSA-C, SCA3, and controls are compared in Table 3. Grade 1 or 2 HCB sign was found in 38 of 41 MSA-C patients (92.7\%), 21 of 26 SCA3 patients (80.8\%), and none of the controls. Grade 1 or $2 \mathrm{HCB}$ was more frequently observed in MSA-C and SCA3 than in controls $(p<0.001)$. There was no statistical difference in the frequency of grade 1 or $2 \mathrm{HCB}$ between MSA-C and SCA3. A grade $2 \mathrm{HCB}$ sign was found in 30 of 41 MSA-C patients (73.2\%), 8 of 26 SCA3 patients (30.8\%), and none of the controls. A grade $2 \mathrm{HCB}$ sign was more frequently observed in MSA-C and SCA3 than in controls $(p<0.001$ and $p=0.004)$, and it was more

Table 2 Hot cross bun (HCB) sign on MRI in MSA and SCA3

\begin{tabular}{|c|c|c|}
\hline & $\begin{array}{l}\text { Grade } 1 \text { or } 2 \text { HCB sign } \\
\text { (vertical or cruciform hyper-intensity) }\end{array}$ & $\begin{array}{l}\text { Grade } 2 \text { HCB sign } \\
\text { (cruciform hyper-intensity) }\end{array}$ \\
\hline \multicolumn{3}{|l|}{ All } \\
\hline MSA $(n=80)$ & $51 / 80(63.8 \%)$ & $39 / 80(48.8 \%)$ \\
\hline MSA-C $(n=41)$ & 38/41 (92.7\%) & $30 / 41(73.2 \%)$ \\
\hline MSA-P $(n=39)$ & 13/39 (33.3\%) & 9/39 (23.1\%) \\
\hline SCA3 $(n=24)$ & $21 / 26(80.8 \%)$ & $8 / 26(30.8 \%)$ \\
\hline Controls $(n=22)$ & $0 / 22(0 \%)$ & $0 / 22(0 \%)$ \\
\hline \multicolumn{3}{|c|}{ Within two years after onset } \\
\hline MSA $(n=43)$ & 25/43 (58.1\%) & $14 / 43(32.6 \%)$ \\
\hline MSA-C $(n=24)$ & 22/24 (91.7\%) & $13 / 24(54.2 \%)$ \\
\hline MSA-P $(n=19)$ & 3/19 (15.8\%) & $1 / 19(5.3 \%)$ \\
\hline SCA3 $(n=4)$ & $2 / 4(50.0 \%)$ & $0 / 4(0 \%)$ \\
\hline \multicolumn{3}{|c|}{ Within three years after onset } \\
\hline MSA $(n=60)$ & $37 / 60(61.7 \%)$ & 26/60 (43.3\%) \\
\hline MSA-C $(n=36)$ & $33 / 36(91.7 \%)$ & $24 / 36(66.7 \%)$ \\
\hline MSA-P $(n=24)$ & 4/24 (16.7\%) & $2 / 24(8.3 \%)$ \\
\hline $\operatorname{SCA3}(n=8)$ & 4/8 (50.0\%) & 0/8 (0\%) \\
\hline
\end{tabular}


Table 3 Hot cross bun (HCB) sign on MRI in MSA-C, SCA3, snd controls

\begin{tabular}{|c|c|c|}
\hline & $\begin{array}{l}\text { Grade } 1 \text { or } 2 \text { HCB sign } \\
\text { (vertical or cruciform hyper-intensity) }\end{array}$ & $\begin{array}{l}\text { Grade } 2 \text { HCB sign } \\
\text { (cruciform hyper-intensity) }\end{array}$ \\
\hline MSA-C & $38 / 41(92.7 \%)$ & $30 / 41(73.2 \%)$ \\
\hline SCA3 & $21 / 26(80.8 \%)$ & $8 / 26(30.8 \%)$ \\
\hline Controls & $0 / 22(0 \%)$ & $0 / 22(0 \%)$ \\
\hline$P$ value for group comparison & $<0.001^{\mathrm{a}}$ & $<0.001^{\mathrm{a}}$ \\
\hline \multicolumn{3}{|c|}{$p$ value for post-hoc group comparisons } \\
\hline MSA-C vs. SCA3 & $0.141^{b}$ & $0.001^{\mathrm{a}}$ \\
\hline MSA-C vs. Controls & $<0.001^{\mathrm{a}}$ & $<0.001^{\mathrm{a}}$ \\
\hline SCA3 vs. Controls & $<0.001^{\mathrm{a}}$ & $0.004^{b}$ \\
\hline MSA-C within 2 years after onset & $22 / 24(91.7 \%)$ & $13 / 24(54.2 \%)$ \\
\hline SCA3 within 2 years after onset & $2 / 4(50.0 \%)$ & $0 / 4(0 \%)$ \\
\hline$P$ value & $0.086^{b}$ & $0.067^{b}$ \\
\hline MSA-C within 3 years after onset & $33 / 36(91.7 \%)$ & $24 / 36(66.7 \%)$ \\
\hline SCA3 within 3 years after onset & $4 / 8(50.0 \%)$ & $0 / 8(0 \%)$ \\
\hline$P$ value & $0.014^{\mathrm{b}}$ & $0.001^{\mathrm{b}}$ \\
\hline
\end{tabular}

${ }^{a}$ Chi-squared test (post-hoc chi-squared tests adjusted for multiple comparison: $P<0.05 / 3=0.0167$ )

${ }^{\mathrm{b}}$ Fisher's exact probability test (post-hoc Fisher's exact probability test adjusted for multiple comparison: $P<0.05 / 3=0.0167$ )

frequently observed in MSA-C than in SCA3 $(p=0.001)$. Among the patients who underwent MRI within 2 years after disease onset, there was no statistically significant difference in the frequency of a grade $2 \mathrm{HCB}$ sign between MSA-C and SCA3, as was in the frequency of grade 1 or $2 \mathrm{HCB}$ sign between MSA-C and SCA3. Among the patients who underwent MRI within 3 years after disease onset, a grade $2 \mathrm{HCB}$ was more frequently observed in MSA-C than in SCA3 $(p=0.001)$, as was grades 1 or $2 \mathrm{HCB}(p=0.014)$.

The HCB had a sensitivity of $91.7 \%$ for MSA-C and a specificity of $50.0 \%$ in patients who underwent MRI within 2 years after disease onset. A grade $2 \mathrm{HCB}$ had a sensitivity of $54.8 \%$ and a specificity of $100 \%$ for MSA-C. On the other hand, the HCB had a sensitivity of $91.7 \%$ for MSA-C and a specificity of $50.0 \%$ in patients who underwent MRI within 3 years after disease onset. A grade 2 HCB sign had a sensitivity of $66.7 \%$ and a specificity of $100 \%$.

Furthermore, patients with SCA3 had a longer disease duration than patients with MSA-C at the first observation of a grade $2 \mathrm{HCB}(11.3 \pm 3.5$ years vs. $2.3 \pm 1.3$ years, $p<0.001)$. This was also true when patients with SCA3 were compared with MSA-C at the first observation of either grade of HCB (5.9 years, [1.2-22.5] vs. 1.8 years, [0.2-5.3], $p<0.001)$.

\section{Orthostatic hypotension}

$\mathrm{OH} 30 / 15$ was observed in 55 of 80 patients with MSA (68.8\%), 27 of 41 with MSA-C (65.9\%), and 28 of 39 with MSA-P (71.8\%). A head-up tilt test within 2 years after disease onset demonstrated $\mathrm{OH} 30 / 15$ in 26 of 44 patients with MSA (59.1\%), 15 of 25 with MSA-C (60.0\%), and 11 of 19 with MSA-P (57.9\%). Similarly, on testing within 3 years after disease onset, $\mathrm{OH} 30 / 15$ was observed in 40 of 62 patients with MSA (64.5\%), 23 of 35 with MSA-C (65.7\%), and 17 of 27 with MSA-P (63.0\%).

However, OH 20/10 was reported in 70 of 80 patients with MSA (87.5\%), 36 of 41 with MSA-C (87.8\%), and 34 of 39 with MSA-P (87.2\%). On testing within 2 years after disease onset, $\mathrm{OH} 20 / 10$ was noted in 35 of 44 patients with MSA (79.5\%), 21 of 25 with MSA-C (84.0\%), and 14 of 19 with MSA-P (73.7\%). On testing within 3 years after disease onset, $\mathrm{OH} \mathrm{20/10} \mathrm{was} \mathrm{observed} \mathrm{in} 54$ of 62 patients with MSA (87.1\%), 32 of 35 with MSA-C (91.4\%), and 22 of 27 with MSA-P (81.5\%).

\section{Discussion}

Our study demonstrated that HCB (either a vertical or cruciform hyperintensity) appeared both in MSA-C and SCA-3, but not in controls. A grade $2 \mathrm{HCB}$ was found more frequently in MSA-C than in SCA3, whereas there was no difference in frequency of grade 1 or 2 HCB between MSA-C and SCA3. On the other hand, among the patients who underwent MRI within 3 years after disease onset, both grade $2 \mathrm{HCB}$ and grade 1 or $2 \mathrm{HCB}$ were found more frequently in MSA-C than in SCA-3. The HCB had a high sensitivity of $91.7 \%$ in the early MSA-C disease course, that is, within 2 years after disease onset. In patients who underwent MRI within 2 or 3 years after disease onset, grade $2 \mathrm{HCB}$ had a high specificity of $100 \%$ in differentiating MSA-C from SCA3. 
The HCB is a highly sensitive finding in MSA-C, even early in the disease course, as noted in several previous studies. In a longitudinal MRI study of MSA, either a vertical or a cruciform hyperintensity were observed in four patients with MSA-C who had undergone MRI within 3 years after onset [6]. A Japanese cohort study of MSA described cruciform HCB in $64.0 \%$ of patients with MSA-C within 2 years and in $87.5 \%$ within 4 years after onset of motor impairment, although a vertical hyperintensity (corresponding to grade 1 in our study) was not evaluated [8]. Higashi et al. reported that all 74 patients with MSA-C (disease duration $2.6 \pm 1.7$ years) had either a pontine midline linear hyperintensity or a complete cruciform HCB [15]. In line with these reports, our study showed that an HCB was frequently observed early in the MSA-C disease course. An HCB of either grade 1 or 2 had a high sensitivity of $91.7 \%$ in MSA-C within 2 years after disease onset, and a grade 2 HCB had a sensitivity of $54.2 \%$ at 2 years and $66.7 \%$ at 3 years after disease onset. Our findings suggest that, in a case of progressive cerebellar ataxia, if an $\mathrm{HCB}$ is not observed on MRI within 2 years after the onset of cerebellar symptoms, it is unlikely that the diagnosis is MSA-C. A recent study showed that either a vertical or a cruciform hyperintensity was detected in $80.1 \%(149 / 186)$ of the patients with MSA-C within 3 years after onset [16]. This result is consistent with that of this study but had a lower frequency. This is because the onset symptoms in the previous study included motor symptoms and autonomic nervous symptoms, and HCB is less likely to be observed within 3 years of onset in cases where autonomic disturbances precede cerebellar symptoms. In striking contrast to our study, however, others have reported a low sensitivity of HCB for MSA-C of 18 to 37\% [17-19]. However, those studies did not assess the appearance of a vertical pontine T2WI hyperintensity (grade 1 in our study), nor was there a clear definition of the presence or absence of an HCB. It was also not stated in those studies who evaluated the images for the sign.

In differentiating MSA-C from SCA3, a grade $2 \mathrm{HCB}$ early in the course is a very specific finding for MSA-C. Among patients imaged within 2 or 3 years after onset, grade $2 \mathrm{HCB}$ was observed in none of those with SCA3, yielding a high specificity of $100 \%$ for distinguishing between MSA-C and SCA3. In line with the results of this study, previous studies that evaluated $\mathrm{HCB}$ in MSA-C and SCA including SCA2, SCA3, SCA7, and SCA8, described that grade $2 \mathrm{HCB}$ was not observed in 39 patients with SCA3 within 3 years after onset [16]. In an evaluation of the HCB in adult cerebellar ataxia that included 33 patients with SCA3 (disease duration $6.3 \pm 6.0$ years), a pontine midline linear hyperintensity was observed 24 (72.7\%), but none had the complete cruciform
HCB [15]. In another study of the HCB sign in SCA that included 76 patients with SCA3, half (38) had a pontine midline hyperintensity corresponding to grade 1 in our study, whereas a cruciform HCB was observed in only one [9]. The higher frequency of a grade $2 \mathrm{HCB}$ in patients with SCA3 in our study is likely because the disease in many of those patients was of longer duration than in the previous studies we cited. Thus, the mean disease duration at the first observation of grade $2 \mathrm{HCBs}$ in patients with SCA3 was $11.3 \pm 3.5$ years, which was considerably later than when the sign appeared in the course of MSA-C. Care must therefore be taken in interpreting this finding in our study because the disease duration at MRI was significantly longer in those with SCA3 than in those with MSA-C.

Although a grade $2 \mathrm{HCB}$ has been reported in several types of SCA $[9,10]$, our study only included patients with SCA3. Therefore, it is unclear whether a grade 2 HCB might appear earlier in the disease course of other SCA types, such that it might be less helpful in differentiating MSA-C from other SCAs. In particular, a grade 2 $\mathrm{HCB}$ was reportedly observed more frequently in SCA2 than in SCA3 $[9,15]$. Kim et al. reported that grade 2 $\mathrm{HCB}$ was observed in 1 of 36 patients with SCA2 within 3 years after onset [16].

$\mathrm{OH}$ is probably not a highly sensitive finding in patients with MSA, especially in the early disease course. On testing within 2 years after disease onset, $\mathrm{OH} 30 / 15$ was observed in only approximately $60 \%$ of patients with MSA in this study. Although some patients with MSA present with $\mathrm{OH}$ as the initial symptom $[18,20], \mathrm{OH}$ does not always appear early in the disease. A retrospective study showed that $56 \%$ of patients had definite MSA-C and $32 \%$ of those with possible/probable MSA$\mathrm{C}$ had a systolic blood pressure decrease of at least 30 $\mathrm{mmHg}$ at the initial clinical visit (disease duration $3.4 \pm$ 1.5 years in definite and $4.2 \pm 2.7$ years in possible/probable MSA-C) [21]. A study of parkinsonian syndromes that were confirmed postmortem stated that symptomatic $\mathrm{OH}$ was observed in only 3 of 15 patients with MSA within the first year after disease onset [22].

Our study has several limitations. First, we evaluated the HCB only on T2WI. Others have reported that the HCB is better visualized on proton density-weighted imaging or $\mathrm{T} 2{ }^{*}$-weighted imaging $[23,24]$. However, because in clinical practice, T2WI is a basic sequence frequently obtained during a brain MRI, we believe that findings of our study regarding the HCB on T2WI are easily applicable in routine practice. Second, we did not have pathology confirmation, so the possibility of misdiagnosis in some of the MSA cases cannot be excluded. Third, we used 1.5 Tesla MRI to evaluate the HCB in this study. The visibility of the HCB with 3 Tesla versus 1.5 Tesla has not been compared. Therefore, we do not 
know if evaluation with 3 Tesla MRI would improve the visibility of the HCB. Although urinary symptoms are important autonomic symptoms for the diagnosis of MSA, as is $\mathrm{OH}$, the frequency of urinary symptoms by disease duration could not be assessed in this study. Finally, in some cases, the middle cerebellar peduncle was not adequately visualized well enough to be evaluated in the axial images, so that the hyperintensity in the middle cerebellar peduncle could not be evaluated in this study. A hyperintensity in the middle cerebellar peduncle on T2WI is reportedly highly specific for differentiating MSA from other neurodegenerative diseases $[5,16,17$, $25,26]$. Combining the HCB with a hyperintensity in the middle cerebellar peduncle may increase the specificity of MSA diagnosis.

\section{Conclusions}

The HCB is a highly sensitive finding in MSA-C, even during the early stages of the disease. A grade $2 \mathrm{HCB}$ at the early stages of the disease is an extremely specific finding for differentiating MSA-C from SCA3. The occurrence of $\mathrm{HCB}$ within 3 years of motor symptom onset should be considered as a supportive feature for diagnosing MSA-C in future diagnostic criteria revisions.

\section{Abbreviations}

MSA: Multiple system atrophy; OH: Orthostatic hypotension; MRI: Magnetic resonance imaging; HCB: Hot cross bun; MSA-C: Cerebellar subtype multiple system atrophy; SCA: Spinocerebellar ataxia; MSA-P: Parkinsonian subtype multiple system atrophy

\section{Acknowledgements}

Not applicable.

\section{Authors' contributions}

AS: Study concept, design, and interpretation of data, writing the manuscript HY and HM: Acquisition and evaluation of the MRI data. YY, TY, SH, and SI: Critical revision of the manuscript for important intellectual content; KK: Collection of the patient data; SK: Conception and design of the study, and revision of the manuscript. All authors read and approved the final manuscript.

\section{Funding}

No funding was received.

\section{Availability of data and materials}

The complete data are available from the corresponding author on reasonable request.

\section{Ethics approval and consent to participate}

This retrospective study was approved by the institutional review board of the Chiba University Graduate School of Medicine, and the need for informed consent was waived.

\section{Consent for publication}

Not applicable.

\section{Competing interests}

The authors declare that they have no conflict of interest.

\section{Author details}

'Department of Neurology, Graduate School of Medicine, Chiba University, Chiba, Japan. ${ }^{2}$ Department of Diagnostic Radiology and Radiation Oncology, Graduate School of Medicine, Chiba University, Chiba, Japan. ${ }^{3}$ Department of
Rehabilitation, Division of Occupational Therapy, Chiba Prefectural University of Health Sciences, Chiba, Japan. ${ }^{4}$ Department of Medical Education, Graduate School of Medicine, Chiba University, Chiba, Japan.

Received: 10 January 2020 Accepted: 20 April 2020

Published online: 27 April 2020

\section{References}

1. Gilman S, Wenning GK, Low PA, Brooks DJ, Mathias CJ, Trojanowski JQ, et al. Second consensus statement on the diagnosis of multiple system atrophy. Neurology. 2008;71:670-6. https://doi.org/10.1212/01.wnl.0000324625.00404. 15

2. Osaki Y, Ben-Shlomo Y, Lees AJ, Wenning GK, Quinn NP. A validation exercise on the new consensus criteria for multiple system atrophy. Mov Disord. 2009:24:2272-6. https://doi.org/10.1002/mds.22826.

3. Kim HJ, Jeon B, Fung VSC. Role of magnetic resonance imaging in the diagnosis of multiple system atrophy. Mov Disord Clin Pract. 2017:4:12-20. https://doi.org/10.1002/mdc3.12404.

4. Schrag A, Kingsley D, Phatouros C, Mathias CJ, Lees AJ, Daniel SE, et al. Clinical usefulness of magnetic resonance imaging in multiple system atrophy. J Neurol Neurosurg Psychiatry. 1998;65:65-71. https://doi.org/10. 1136/jnnp.65.1.65

5. Schrag A, Miszkiel K, Morris HR, Mathias CJ, Lees AJ, Quinn NP. Differentiation of atypical parkinsonian syndromes with routine MRI Neurology. 2000;54:697-702. https://doi.org/10.1212/wnl.54.3.697.

6. Horimoto Y, Aiba I, Yasuda T, Ohkawa Y, Katayama T, Yokokawa Y, et al. Longitudinal MRI study of multiple system atrophy - when do the findings appear, and what is the course? J Neurol. 2002;249:847-54. https://doi.org/ 10.1007/s00415-002-0734-0.

7. Abe K, Hikita T, Yokoe M, Mihara M, Sakoda S. The "cross" signs in patients with multiple system atrophy: a quantitative study. J Neuroimaging. 2006; 16:73-7. https://doi.org/10.1177/1051228405279988.

8. Watanabe H, Saito Y, Terao S, Ando T, Kachi T, Mukai E, et al. Progression and prognosis in multiple system atrophy: an analysis of 230 Japanese patients. Brain. 2002;125:1070-83. https://doi.org/10.1093/brain/awf117.

9. Lee YC, Liu CS, Wu HM, Wang PS, Chang MH, Soong BW. The "hot cross bun" sign in the patients with spinocerebellar ataxia. Eur J Neurol. 2009;16: 513-6. https://doi.org/10.1111/j.1468-1331.2008.02524.x.

10. Ozaki K, Doi H, Mitsui J, Sato N, likuni Y, Majima T, et al. A novel mutation in ELOVL4 leading to spinocerebellar ataxia (SCA) with the hot cross bun sign but lacking erythrokeratodermia: a broadened spectrum of SCA34. JAMA Neurol. 2015;72:797-805. https://doi.org/10.1001/jamaneurol.2015.0610.

11. Paulson H. Machado-Joseph disease/spinocerebellar ataxia type 3. Handb Clin Neurol. 2012;103:437-49. https://doi.org/10.1016/B978-0-444-51892-7. 00027-9.

12. Tsuji S, Onodera O, Goto J, Nishizawa M. Study group on ataxic diseases. Sporadic ataxias in Japan- a population-based epidemiological study Cerebellum. 2008;7:189-97. https://doi.org/10.1007/s12311-008-0028-x.

13. Diallo A, Jacobi H, Cook A, Labrum R, Durr A, Brice A, et al. Survival in patients with spinocerebellar ataxia types 1, 2, 3, and 6 (EUROSCA): a longitudinal cohort study. Lancet Neurol. 2018;17(4):327-34. https://doi.org/ 10.1016/S1474-4422(18)30042-5.

14. Consensus statement on the definition of orthostatic hypotension, pure autonomic failure, and multiple system atrophy. The Consensus Committee of the American Autonomic Society and the American Academy of Neurology. Neurology. 1996;46:1470.

15. Higashi M, Ozaki K, Hattori T, Ishii T, Soga K, Sato N, et al. A diagnostic decision tree for adult cerebellar ataxia based on pontine magnetic resonance imaging. J Neurol Sci. 2018;387:187-95. https://doi.org/10.1016/j. jns.2018.02.022.

16. Kim M, Ahn JH, Cho Y, Kim JS, Youn J, Cho JW. Differential value of brain magnetic resonance imaging in multiple system atrophy cerebellar phenotype and spinocerebellar ataxias. Sci Rep. 2019;9:17329. https://doi. org/10.1038/s41598-019-53980-y.

17. Lee EA, Cho HI, Kim SS, Lee WY. Comparison of magnetic resonance imaging in subtypes of multiple system atrophy. Parkinsonism Relat Disord. 2004;10:363-8. https://doi.org/10.1016/j.parkreldis.2004.04.008

18. Yabe I, Soma H, Takei A, Fujiki N, Yanagihara T, Sasaki H. MSA-C is the predominant clinical phenotype of MSA in Japan: analysis of 142 patients with probable MSA. J Neurol Sci. 2006;249:115-21. https://doi.org/10.1016/j. jns.2006.05.064. 
19. Pradhan S, Tandon R. Relevance of non-specific MRI features in multiple system atrophy. Clin Neurol Neurosurg. 2017;159:29-33. https://doi.org/10. 1016/j.clineuro.2017.05.008.

20. McKay JH, Cheshire WP. First symptoms in multiple system atrophy. Clin Auton Res. 2018;28:215-21. https://doi.org/10.1007/s10286-017-0500-0.

21. Lin DJ, Hermann KL, Schmahmann JD. The diagnosis and natural history of multiple system atrophy, cerebellar type. Cerebellum. 2016;15:663-79. https://doi.org/10.1007/s12311-015-0728-y.

22. Wenning GK, Scherfler C, Granata R, Bösch S, Verny M, Chaudhuri KR, et al. Time course of symptomatic orthostatic hypotension and urinary incontinence in patients with postmortem confirmed parkinsonian syndromes: a clinicopathological study. J Neurol Neurosurg Psychiatry. 1999; 67:620-3. https://doi.org/10.1136/jnnp.67.5.620

23. Kasahara S, Miki Y, Kanagaki M, Kondo T, Yamamoto A, Morimoto E, et al. "Hot cross bun" sign in multiple system atrophy with predominant cerebellar ataxia: a comparison between proton density-weighted imaging and T2-weighted imaging. Eur J Radiol. 2012;81:2848-52. https://doi.org/10. 1016/j.ejrad.2011.12.012.

24. Deguchi K, Ikeda K, Kume K, Takata T, Kokudo Y, Kamada M, Touge T, et al. Significance of the hot-cross bun sign on T2*-weighted MRI for the diagnosis of multiple system atrophy. J Neurol. 2015;262:1433-9. https://doi. org/10.1007/s00415-015-7728-1.

25. Bürk K, Bühring U, Schulz JB, Zühlke C, Hellenbroich Y, Dichgans J. Clinical and magnetic resonance imaging characteristics of sporadic cerebellar ataxia. Arch Neurol. 2005;62:981-5. https://doi.org/10.1001/archneur.62.6.981.

26. Massey LA, Micallef C, Paviour DC, O'Sullivan SS, Ling H, Williams DR, et al. Conventional magnetic resonance imaging in confirmed progressive supranuclear palsy and multiple system atrophy. Mov Disord. 2012;27:175462. https://doi.org/10.1002/mds.24968.

\section{Publisher's Note}

Springer Nature remains neutral with regard to jurisdictional claims in published maps and institutional affiliations.

Ready to submit your research? Choose BMC and benefit from:

- fast, convenient online submission

- thorough peer review by experienced researchers in your field

- rapid publication on acceptance

- support for research data, including large and complex data types

- gold Open Access which fosters wider collaboration and increased citations

- maximum visibility for your research: over $100 \mathrm{M}$ website views per year

At $\mathrm{BMC}$, research is always in progress.

Learn more biomedcentral.com/submissions 